\title{
El legado de utensilios en el pensamiento de Neracio (jurista del periodo de Trajano y Adriano)
}

\section{The legacy of utensils in neratius philosophy (jurist of Trajan and Hadrian's period)}

AUTOR: Yuri González Roldán

SUMARIO: I. Introducción. II. Fundo provisto con todo aquello necesario para la producción (fundus instructus) y fundo con los aperos o con las herramientas de trabajo (fundus cum instrumento) III. Casa amueblada (domus instructa). IV. Utensilios de un negocio (instrumentum tabernae). V. Reflexiones finales.

Resumen: La publicación de interesantes estudios respecto al fundus instructus sirve como una ocasión para reflexionar sobre el problema en relación a un jurista determinado y a su trabajo, Neracio Prisco. La opinión de Neracio sobre el argumento se encuentra en Ulpiano, libro vicesimo ad Sabinum en D. 33.7.12.35 y D.33.7.12.43, en UIpiano, libro trigesimo secundo ad edictum en D. 19.2.19.2, in D. 33.7.23, en Paulo, libro secundo ad Vitellium en D. 33.7.18.2, libro tertio ad Neratium en D. 33.7.24, libro quarto ad Sabinum en D. 33.7.13 pr.-1 y Ulpiano, libro vicesimo ad Sabinum en D. 33.7.12.4. Estudié varios problemas, por ejemplo: fundus cum instrumento, domus instructa y el instrumentum tabernae.

Abstract: The publication of interesting studies of fundus instructus is an occasion for reflection about this problem of individual jurist and works,
Nerazio Prisco. The opinion of Neratius are in Ulpiano, libro vicesimo ad Sabinum in D. 33.7.12.35 and D.33.7.12.43, in Ulpiano, libro trigesimo secundo ad edictum in D. 19.2.19.2, in D. 33.7.23, in Paulus, libro secundo ad Vitellium in D. 33.7.18.2, libro tertio ad Neratium in D. 33.7.24, libro quarto ad Sabinum in D. 33.7.13 pr.-1 and Ulpiano, libro vicesimo ad Sabinum in D. 33.7.12.4. I studied differents problems for example: fundus cum instrumento, domus instructa and instrumentum tabernae.

\section{Introducción}

Debido a que existen varios autores que ya se han dedicado al estudio del legado de utensilios (instrumentum) como citaremos en el transcurso de la presente investigación, se podría pensar en la falta de utilidad de un nuevo estudio sobre el argumento, sin embargo, según nuestra opinión, el tema podría seguir siendo tratado bajo nuevos perfiles. Nuestra propuesta no consistirá en presentar el análisis del problema desde el punto de vista cronológico, por ejemplo de los orígenes hasta la jurisprudencia severiana, sino simplemente 
tratar de explicar la visión que Neracio tuvo sobre el mismo en su contexto histórico. Tal prospectiva permitirá determinar la aportación precisa del jurista y las soluciones que propone sobre diferentes problemas que se refieren a este tipo de legado que en otro modo podrían pasar inobservados.

Neracio tiene un amplio conocimiento de los elementos de los que está compuesto el fundo rústico, no sólamente porque conoce las obras de Catón, De Agri cultura, de Varrón, De re rustica, de Columela, De re rustica, o de Plinio, Naturalis Historia, sino sobre todo porque el jurista proviene de una familia de antigua nobleza sanita originaria de Saepinum ${ }^{1}$ en donde la unión con la tierra era muy fuerte. Tal hecho se percata en su evidente conocimiento de economía agraria que emerge en cada pasaje motivo de nuestra investigación; por ello, su visión sobre el fundo rústico, bajo el perfil jurídico y práctico, enriquece la materia de los legados, específicamente los que tienen por objeto los instrumentos de trabajo (instrumentum fundi), argumento que el jurista utilizará como modelo de interpretación para otros legados parecidos, como por ejemplo los muebles y utensilios de una casa (instrumentum domus) y de un negocio (tabernae).

Como veremos enseguida, en edad antonina la identidad conceptual considerada por Labeón entre fundo provisto con todo aquello necesario para la producción (fundus instructus) y fundo con los aperos o con las herramientas de trabajo (fundus cum instrumento) ya no existe; efectivamente, los objetos integrantes del fundo adquieren un significado diferente de los que tenían en origen, comprendiendo no solo aquellos objetos de materiales humildes sino se incorporarán inclusive materiales preciosos como marfil, carey, plata, oro y piedras preciosas; además el casco de la hacienda (villa) no es solo considerada una parte del fundo sino el lugar usado por el pater familias para su propio beneficio y comodidad.

Los textos materia de estudio se encuentran en el libro cuarto de

\footnotetext{
${ }^{1}$ Sobre la vida de Neracio Prisco ver por ejemplo, W. Kunkel, Herkunft und soziale Stellung der römischen Juristen, Graz-Wien-Köln, 1967, 144 ss, F. Schulz, Storia della giurisprudenza romana, trad., Firenze, 1968, 190, F. Grelle, L'autonomia cittadina fra Traiano e Adriano, Napoli, 1972, 156 ss, F. Casavola, Giuristi Adrianei, Napoli, 1980, 272 ss, V. Scarano Ussani, Empiria e Dogmi. La scuola proculeiana fra Nerva e Adriano, rist. Torino, 1990, 21 ss, G. Camodeca, La carriera del giurista L. Neratius Priscus en AAN. 87, 1976, 32 ss., del mismo autor II giurista L.Neratius Priscus Cos. Suff. 97 nuovi dati su carriera e famiglia en SDHI, 73, 2007, 291 ss., T. Masiello, introducción a la obra de S. Nappi, lus finitum, Bari, 2005, 7 ss.
} 
las epístolas de Neracio citado por Ulpiano, libro vicesimo ad Sabinum en D. 33.7.12.35 y D.33.7.12.43, en la misma obra pero, en un lugar no identificado, una carta recordada por Ulpiano, libro trigesimo secundo ad edictum en D. 19.2.19.2, en el segundo libro de sus responsos en D. 33.7.23 y en textos de obras tampoco identificadas como sería el caso de la mención de Neracio hecha por Paulo, libro secundo ad Vitellium en D. 33.7.18.2, libro tertio ad Neratium en D. 33.7.24, libro quarto ad Sabinum en D. 33.7.13 pr.-1 y Ulpiano, libro vicesimo ad Sabinum en D. 33.7.12.4.

\section{Fundo provisto con todo aquello necesario para la producción (fundus instructus) y fundo con los aperos o con las herramien- tas de trabajo (fundus cum instrumento).}

Entre los tipos de legado tratados por Neracio se encuentran aquellos que tienen por objeto el fundo provisto o con todo aquello necesario para la producción (fundus instructus) y el fundo con los aperos o instrumentos de trabajo (fundus cum instrumento). En origen parecería existir identidad conceptual entre ambos conceptos como recuerda Labeón, libro primo piqanîn a Paulo epitomatorum en D. 33.7.5: si cui fundum et instrumentum eius legare vis, nihil interest, quomodo leges'fundum cum instrumento' an 'fundum et instrumentum' an 'fundum instructum' (Si quieres legar a alguien un fundo y sus utensilios, no importa de que modo se los legues, si el fundo con los utensilios o el fundo y los utensilios o el fundo provisto con los elementos necesarios para la producción), pero en edad antonina el fundo provisto, con todo aquello necesario para la producción (fundus instructus) adquirirá un significado más amplio respecto al fundo con los utensilios de trabajo (fundus cum instrumento).

En un texto de Ulpiano, libro vicesimo ad Sabinum en D. 33.7.12.35 encontramos una cita al libro cuarto de las epístolas de $\mathrm{Neracio}^{2}$, en donde el jurista de la edad de Trajano habría elencado y explicado a un personaje llamado Rufino ${ }^{3}$ los objetos de los que estaría compues-

\footnotetext{
${ }^{2}$ Los textos pertenecientes al libro cuarto de las epístolas de Neracio llegados a nuestros dias son sólamente D. 33.7.12.35 e 43. Tales pasajes además de D. 19.2.19.2 son la totalidad de los que existen de los libri epistularum de Neracio como puede comprobarse en O. Lenel, Palingenesia luris Civilis, 1, rist. Roma, 2000, 763 ss. Sobre este punto ver R. Greiner, Opera Neratii, Karlsruhe, 1973, 134.

${ }^{3}$ Existen dudas sobre la identificación del personaje al que va dirigida la carta de Neracio. Quisieramos recordar sólamente algunas personas que tienen tal nombre y que vivieron en el periodo en que escri-
} 
to el fundo provisto con los elementos necesarios para la producción (fundus instructus):

Neratius quoque libro quarto epistularum Rufino respondit instructo fundo et suppellectilem et vina et mancipia non solum ad cultum custodiamve villae, sed etiam quae ut ipsi patri familias in ministerio ibi essent, legato cedere.

También Neracio en el libro cuarto de las epístolas respondió a Rufino que en el legado de fundo provisto con todos los elementos necesarios para la producción se encuentran incorporados los muebles, los vinos y los esclavos, no solo aquellos destinados a sembrar o a cuidar el casco de la hacienda, sino también aquellos que están al servicio del pater familias.

Entre los elementos de los que está compuesto el fundo provisto con todos los elementos necesarios para la producción (fundus instructus) se encuentra incluído el mobiliario (supellex), el origen de tal palabra se encuentra indicada por Celso, libro nono decimo digestorum en D. 33.10.7 pr, el cual citando a Labeón, explica que en origen, las cosas de uso personal de los militares que partían a una determinada legión se colocaban bajo una piel (quod olim his, qui in legationem proficiscerentur, locari solerent, quae sub pellibus usui forent). En edad antonina el mobiliario (suppellex) tendría un significado diferente correspondiendo a todos los objetos muebles del pater familias que existen en un fundo y que tendrán una función doméstica, excluyéndose, según una parte de la jurisprudencia, los objetos de metales preciosos, vestidos y animales ${ }^{4}$, como por ejemplo5: las mesas (men-

bió el jurista. Plinio, por ejemplo, mandó una carta a Rufino (Ep. 8.18) identificándose probablemente con Fadio Rufino, vir egregius como se encuentra recordado en Ep. 9.23.4 cónsul suffectus del año 113 d.C. Además existió un tal Trebonio Rufino, amigo de Plinio citado en Ep. 4.22.1 y 2. Sobre este argumento ver K. Wachtel, s.v. Rufinus en Prosopographia Imperii Romani, VII.1, Berolini, 1999, 95.

${ }^{4}$ Así Pomponio, libro sexto ad Sabinum en D. 33.10.1: supellex est domesticum patris familiae instrumentum, quod neque argento aurove facto vel vesti adnumeretur (Son mobiliario o parte del ajuar los utensilios domésticos del padre de familia que no sean hechos de plata, oro labrado o sean ropa). Florentino, libro undecimo institutionum en D. 33.10.2: id est res moventes non animales (esto es, cosas muebles no animadas). Respecto a los objetos hechos de metales preciosos destinados al uso doméstico parecería existir una controversia jurisprudencial entre Celso, Pomponio y Paulo, porque mientras Celso, libro nono decimo digestorum en D. 33.10.7.1 había hecho notar el cambio existente en la sociedad romana, en donde el mobiliario no era constituído de materiales ordinarios sino de objetos hechos de materiales finos como el marfil, carey, plata, oro, gemas (...nam fictili aut lignea aut vitrea aut aerea denique suppellectili utebantur, nunc ex ebore atque testudine et argento, iam ex auro etiam atque gemmis supellectili utuntur...) Pomponio continuaba a excluírlos. Paulo, libro quarto ad 
sae), las bases de la mesa artísticamente trabajadas (trapezophora), las mesas de tres patas (delficae), las sillas (subsellia), los bancos (scamna), las camas (lecti) incluyéndose aquellas bañadas en plata (etiam inargentati), los colchones (culcitae), las sabanas (toralia), el calzado de casa (impilia), las cacerolas para el agua (vasa aquaria), los recipientes (pelves), las palanganas para lavarse las manos (aquiminalia), los candelabros (candelabra), las lámparas (Iucernae), las garrafas usadas como braceros (trulla). Deben incluírse además los recipientes metálicos comunes sin una específica función (vasa aenae vulgaria), los cajones (capsae) y los armarios (armaria) no destinados a la colocación de libros o vestidos, la vajilla de cristal para comer y beber (vitrea escaria et potoria) de poco o alto valor.

Según Neracio, para determinar los elementos de los que estaba compuesto el fundo con todo aquello destinado a la producción (fundus instructus) era necesario considerar como punto de referencia el casco de la hacienda (la villa o il praetorium 6 ) ya que formaba parte del mismo fundo; efectivamente el término mobiliario (supellex) tiene como significado una universalidad de cosas existentes en la casa

Sabinum en D.33.10.3 e 5 acepta la tesis de Celso e informa además que los recipientes, las cubetas para lavarse las manos, las mesas y las camas no obstante hubieran sido hechos totalmente de metales y piedras preciosas continuarían a considerarse muebles: ...nam et pelves argenteas et aquiminalia argentea et mensas et lectos inargentatos vel inauratos atque gemmatos in supellectili esse non dubitatur, usque adeo, ut idem iuris sit et si tota argentea vel aurea sint. 5. Nec interest, cuius materiae sunt res... No sabemos cual haya sido la posición de Neracio sobre el argumento, pero cuando trataremos el problema del legado de casa amueblada (domus instructa) veremos como probablemente el jurista habría incluído también los objetos de materiales preciados en tal concepto.

${ }^{5}$ En el elenco citado mencionamos el pasaje de Paulo, libro quarto ad Sabinum en D. 33.10 .3 pr.-5 incluyendo únicamente las cosas que según nuestra opinión eran consideradas como mobiliario por Neracio y no aquellas de las que parecería existir controversia jurisprudencial, porque no sabemos a ciencia cierta la tesis del jurista sobre tal aspecto.

${ }^{6}$ Debemos distinguir entre casa patronal ( $v i l l a$ ) y edificio de casa (aedes o domus) como distingue Florentino, libro octavo institutionum en D. 50.16.211, el cual consideraba incluida en la palabra fundus el edificio en su integridad y la totalidad del area ('Fundi' appellatione omne aedificium et omnis ager continetur). Si los edificios son de uso urbano son denominados casas (aedes), mientras que en el caso de edificios rústicos el término correcto es casa patronal (villae): sed in usu urbana aedificia 'aedes', rustica 'villae' dicuntur. En la ciudad un lugar sin construcción es llamado 'area', pero en la zona rural se denomina 'campo': locus vero sine aedificio in urbe 'area', rure autem 'ager' appellatur. Y el mismo campo con una construcción es llamado fundo: idemque ager cum aedificio 'fundus' dicitur. El término praetorium fue usado por Neracio en su libro cuarto regularum en D. 8.3.2 pr.: rusticorum praediorum servitutes sunt licere altius tollere et officere praetorio vicini, vel cloacam habere licere per vicini domun vel prae- 

comodidad.

Dentro de los otros bienes integrantes del fundo destinado a la producción (fundus instructus), Neracio incluye el vino, usando el término al plural 'vina', probablemente para subrayar los diferentes tipos: por una parte el vino destinado a satisfacer las necesidades propias del pater familias y de sus posibles invitados y por otra, el vino de calidad inferior para agregarle agua y producir la bebida llamada lora para los esclavos ${ }^{8}$. Evidentemente los vinos citados por el jurista son el resultado de la vendemia después de la cosecha de la uva producida por el fundo concedido en legado ${ }^{9}$. Neracio cita solo el vino y no otros productos de la tierra como el trigo o las aceitunas, porque el jurista responde a una pregunta específica formulada por Rufino, la determinación de los elementos del fundo provisto de todo lo necesario para la producción (fundus instructus), probablemente porque este último

torium, vel protectum habere licere (Son servidumbres de los predios rústicos: que sea permitido alzar más alto y perjudicar la luz del vecino o que sea permitido tener una cloaca que pase por la casa del vecino o por su hacienda o que sea permitido tener protección de tejado apoyado en la propiedad ajena).. ${ }^{7}$ En edad republicana Alfeno distinguió entre utensilios de la casa patronal (instrumentum villae) y el mobiliario como se constata en un pasaje del epítome de Paulo al libro segundo digestorum del presente jurista en D. 33.7.16 pr.: villae instrumento legato supellectilem non contineri verius est (Resulta verdadero que el legado de utensilios de la casa patronal no incluye el mobiliario). Tal distinción no fue aceptada por Paulo, libro tertio decimo responsorum en D. 33.7.19.1.: Paulus respondit villae instrumento neque fructus repositos neque equitium contineri, suppellectile autem legato cedere...(Paulo respondió que en el apero o instrumentos de la casa patronal no se incorporan los frutos almacenados ni los animales pero el mobiliario o menaje cede al legado). La diferencia entre los dos conceptos se encuentra explicada en R. Astolfi, Studi sull'oggetto dei legati in diritto romano, 2, Padova, 1969, 27 ss, en el sentido de que el menaje o mobiliario sirve al pater familias en modo directo mientras que los utensilios de trabajo o aperos (instrumentum villae) diréctamente al casco de la hacienda e indirectamente al pater familias. En el pasaje que estamos analizando de Neracio no resulta necesario distinguir los dos conceptos porque evidentemente en el fundo provisto con todo aquello destinado a la producción (fundus instructus) fueron incluídos todos los elementos del fundo útiles al pater familias directamente o indirectamente.

${ }^{8}$ Consideramos las palabras de Catón, De Agri cultura 28: ...si voles, lavito paulatim: erit lorea familiae quod bibat. El autor en el pasaje 66 de la misma obra trata de las raciones de vino destinadas a los esclavos (familia servorum) y sobre este aspecto toma en consideración el presupuesto que el vino hubiera sido producido en el fundo (vinum familiae: ubi vindemia facta erit, loram bibant...). Como veremos más adelante, tal hecho podría servir como fundamento a la tesis que el problema analizado por Neracio corresponda a un fundo en donde se cultiva vid, porque si en el fundo provisto con todos los elementos necesarios para la producción (fundus instructus) fueron incluídos los vinos, no es razonable excluir que también fueran empleados para dar de beber a los esclavos que cultivaban el fundo.

${ }^{9}$ Sobre la vendimia ver Catón, De Agri cultura 28 e 29. A. Di Porto, Impresa agricola ed attivitá collegate nell'economia della <<villa >>. Alcune tendenze organizzative in Sodalitas. Scritti in O. di A. Guarino, 7, Napo- 
habría debido recibirlo en un legado o había sido designado heredero en un testamento y debía entregarlo al legatario. Por el contrario, si el jurista en su responso hubiera tenido como modelo cualquier tipo de fundo diferente al considerado en la epístola habría incluído otros bienes; por ejemplo, el trigo necesario para la producción del pan. Esta afirmación se puede comprobar en el texto de Escévola, libro sexto decimo digestorum en D. 33.7.6, que incluye en el fundo provisto con todo aquello necesario para la producción (fundus instructus) no únicamente el vino sino también el trigo ${ }^{10}$.

En conclusión, si en el texto analizado en este momento viene considerado solo el vino como uno de los elementos de los que está compuesto el fundus instructus sin incluir el trigo es porque Neracio tenía en mente un fundo destinado a la actividad vinícola ${ }^{11}$ del cual había sido beneficiado (o estaba obligado a cumplir) Rufino en base a un legado destacando como los vinos producidos en tal fundo formaban parte del legato.

Los otros elementos del fundo provisto con todos los elementos necesarios para la producción (fundus instructus) son los esclavos ${ }^{12}$.

li, 1984, 3235 ss, llegó a la conclusión que a partir del I siglo a.C. existía una importante actividad que giraba alrededor del fundo, además del cultivo, la transformación de los productos producidos en el fundo, como sería el caso de la producción de vino.

${ }^{10}$ Nepoti legaverat quae certa regione praedia habuerat ut instructa sunt, cum vino grano...

${ }^{11}$ Quisieramos notar como a los inicios de la edad imperial Columela, en el libro tercero de su obra De re rustica, recuerda que ningún cultivo conviene tanto como el del agricultor que siembra vid 3.3.2.... Interim studiosi agricolationis hoc primum docendi sunt uberrimum esse reditum vinearum. Lo mismo piensa Plinio, nat. hist. 18.29 citando Catón: Ille (Cato) in agro quaestuosissimam iudicat vitem, non frustra, quoniam ante omnia de inpensae ratione cavit... Tal situación haría pensar (también estadísticamente hablando) que el fundo al que hacía referencia Rufino había tenido como finalidad el cultivo de la vid para la producción del vino.

${ }^{12}$ Varrón, De re rustica 1.17.1 hace la distinción entre tres tipos de instrumentos (instrumentum): vocale (esclavos), semivocale (animales) y mutum (utensilios) ...instrumenti genus vocale et semivocale et mutum: vocale, in quo sunt servi, semivocale, in quo sunt boves, mutum, in quo sunt plaustra. Si para Neracio los esclavos fueron incorporados en el fundo provisto con todo aquello necesario para la producción (fundus instructus) significa que los esclavos (mancipia) formaban parte del instrumentum como, a partir del periodo republicano, toda la jurisprudencia había aceptado. Aislada permanece la tesis contraria de Alfeno, recordada por Ulpiano, libro vicesimo ad Sabinum en D. 33.7.12.2, porque, en su opinión, ningún ser viviente era considerado un instrumentum: Alfenus autem, si quosdam ex hominibus aliis legaverit, ceteros, qui in fundo fuerunt, non contineri instrumentum ait, quia nihil animalis instrumenti esse opinabatur... (Pero Alfeno dice que si hubiera legado a unos algunos esclavos, no se comprenden en los utensilios los demás que existan en el fundo, porque opinaba que ningún ser vivo se comprendía dentro de los utensilios). Probablemente el concepto de utensilios (instrumentum) en origen estaba destinado a los seres inanimados como por ejemplo las herramientas necesarias para sembrar (tesis seguida todavía por Alfeno) y después se 
Neracio distingue en tres categorías: los destinados a la siembra, al cuidado del casco de la hacienda y al servicio del pater familias. En lo que respecta a la primera categoría debemos recordar la organización de la actividad agrícola en varios niveles como aclaraba Sabino, recordado por Ulpiano, libro vicesimo ad Sabinum en D. 33.7.8 $\mathrm{pr}^{13}$ : Ios homines qui agrum colunt (los agricultores), los vilici (los capataces ${ }^{14}$ ), los monitores (vigilantes de la actividad agrícola). Entre los trabajadores agrícolas Columela, De re rustica 11.1.12-16 ${ }^{15}$, incluye el arator (el que siembra), fossor (el que hace hoyos), foeni sector (el que riega), arborator (el que cultiva los árboles de fruto) e vinitor (el que cultiva la vid). Debemos recordar también los compeditis (esclavos que eran castigados con cadenas) y que debían seguir trabajando ${ }^{16}$.

Dentro de los esclavos que se dedicaban al cuidado de la casa patronal encontramos los atrienses (porteros o mayordomos) que tenían la función de vigilar la casa y entre los esclavos destinados al servicio del pater familias debemos considerar aquellos que limpiaban el casco de la hacienda y los que administraban el fundo. Dentro de los primeros podemos recordar los scoparii (los barrenderos), los topiarii (los jardineros), los pastores (pastores) y los saltuarii (guardabosques) si la hacienda contaba con bosques, pastizales y ganado ${ }^{17}$;

incorporarían los esclavos. Sobre este argumento ver A. Steinwenter, Fundus cum instrumento. Eine agrarund rechtsgeschichtliche Studie, Wien-Leipzig, 1942, 26 ss. V. Arangio-Ruiz, s.v. instrumentum en Dizionario epigrafico di antichitá romane, 4.1, Roma, 1946, 59 ss. P. Rasi, Le pertinenze e le cose accessorie, Padova, 1954, 28, M. Horvat, <<Servi >> e <<legatum fundi>> nella giurisprudenza classica en Antologia giuridica romanistica ed antiquaria, 1, Milano, 1968, 213 ss, del mismo autor, 'Legatum fundi' e 'servi' en Studi in onore di E. Volterra, 5, Milano, 1971, 89 ss, Astolfi, Studi sull'oggetto dei legati in diritto romano, 2, cit., 2 ss. Una propuesta de explicación a la tesis de Alfeno fue presentada por M. A. Ligios, Interpretazione giuridica e realtá economica dell'<<instrumentum fundi>> tra il I sec. a.C. e il III sec.d.C., Napoli, 1996, 33 ss. Según la investigadora Alfeno aceptaba la tesis filosófica aristotélica por la que los esclavos y los animales, como miembros de una especie superior, no podían ser considerados como utensilios (instrumentum).

${ }^{13}$...Sabinus libris ad Vitellium evidenter enumerat. quaerendi, veluti homines qui agrum colunt, et qui eos exercent praepositive sunt is, quorum in numero sunt vilici et monitores...

${ }^{14} \mathrm{El}$ vilicus debía estar presente en el fundo siempre como recuerda Columela, De re rustica, 11.21-26, sin excluír su facultad de efectuar compras y ventas en la ciudad y en los mercados: ....Non urbem, non ullas nundinas, nisi vendendae aut emendae rei necessariae causa, frequentaverit. Neque enim coloniae suae terminos egredi debet nec absentia sua familiae cessandi aut delinquendi spatium dare...Sobre la actividad en el mercado del vilicus ver Di Porto, Impresa agricola ed attivitá collegate nell'economia della $<<v i l l a>>$. Alcune tendenze organizzative, cit., 3267 ss.

${ }^{15}$...Nam et arator reperiatur aliquis bonus et optimus fossor aut foeni sector nec minus arborator et vinitor...

${ }^{16}$ Las referencias a los compeditis se encuentran en Catón, de agric. 55 y 56 cuando se refiere a los alimentos y al vino que se les proporcionará a los esclavos.

${ }^{17}$ Para identificar los esclavos destinados al servicio del dominus tomamos en consideración el pasaje de 
en la segunda categoría se encontraban el actor y el dispensator que tenían funciones administrativas ${ }^{18}$.

Confrontando el contenido del texto del cuarto libro de las epístolas de Neracio con la posición de Sabino que se encuentra en Ulpiano, libro vicesimo ad Sabinum en D. 33.7.12.27 resulta interesante verificar si el jurista antonino aceptase totalmente la afirmación de Sabino y Casio que consideraban el concepto de fundo provisto con todo aquello necesario para la producción (fundus instructus) en un sentido más amplio de fundo con los aperos o instrumentos de trabajo (fundus cum instrumento), contrariamente a Labeón, libro primo piqanîn a Paulo epitomatorum en D. 33.7.5. que consideraba los dos conceptos como sinónimos ${ }^{19}$. La tesis de Sabino (anteriormente afirmada por Servio y Alfeno ${ }^{20}$ ) durante el periodo clásico era mayormente aceptada como se destaca en D. 33.7.12.27: quam sententiam cottidie increscere et invalescere videmus (cuya opinión vemos que diariamente se extiende y robustece).

Ulpiano, libro vigesimo ad Sabinum en D. 33.7.8.1, el cual afirma que en ciertas regiones son incorporados dentro de los utensilios de trabajo, si la hacienda fuera importante (al mismo modo del caso tratado por Neracio en el texto motivo de nuestro estudio), los atrienses (porteros), los scoparii (barrenderos); los topiarii (jardineros) si la casa patronal hubiera tenido jardines, los pastores (pastores) y los saltuarii (guardabosques), si además hubiera tenido bosques, pastizales y ganado: quibusdam in regionibus accedunt instrumento, si villa cultior est, veluti atrienses scoparii, si etiam virdiaria sint, topiarii, si fundus saltus pastionesque habet greges pecorum pastores saltuarii. Un estudio sobre el texto fue realizado por Ligios, Interpretazione giuridica e realtá economica dell'<<instrumentum fundi >> tra il I sec. a.C. e il III sec.d.C., cit., 229 ss.

${ }^{18}$ La referencia al actor se encuentra en Escévola, libro quarto decimo digestorum en D. 34.4 .31 pr.: ...Stichum his praediis, in quae translatus est, actorem cedere...(el administrador Estico se incorporaba a los predios). El dispensator es definido por Varrón, de lingua lat. 4: Dispensator, cui creditur administratio pecuniarum, quia prius quam dabant pecuniam, non numerabant, sed appendebant eam (Se llamaba dispensator el que administraba el dinero porque más bien en lugar de contarlo lo pesaba, appendere = pesar). Además es recordado por Pomponio, libro sexto ad Sabinum en D. 50.16 .166 pr.....dispensator non esse servorum urbanorum numero...(el dispensator no es considerado un esclavo de la ciudad). Sobre el argumento ver Ligios, Interpretazione giuridica e realtá economica dell'<<instrumentum fundi >> tra il I sec. a.C. e il III sec.d.C., cit. 51. ${ }^{19}$ En el mismo sentido R. Astolfi, Et Cassius apud Vitellium notat en IURA, 16, 1965, 117 ss, y Studi sull'oggetto dei legati in diritto romano, 2, cit. $13 \mathrm{ss,} \mathrm{Ligios,} \mathrm{Interpretazione} \mathrm{giuridica} \mathrm{e} \mathrm{realtá} \mathrm{economica}$ dell'<<instrumentum fundi>> tra il I sec. a.C. e il III sec.d.C., cit., 26 n. 26.

${ }^{20} \mathrm{Alfeno}$ tenía un concepto de fundo provisto con todo lo necesario para la producción (fundus instructus) más amplio de fundo con aperos o herramientas de trabajo (fundus cum instrumento) como se observa en el texto de tal jurista, libro secundo digestorum a Paulo epitomatorum en D.33.7.16.2: quidam uxori fundum, uti instructus esset, in quo ipse habitabat, legavit. consultus de mulieribus lanificis an instrumento continerentur, respondit non quidem esse instrumenti fundi, sed quoniam ipse pater familias, 
Debido a que Neracio habría considerado válida la tesis de Sabino, Ulpiano recuerda el pensamiento del jurista antonino en el libro vigésimo ad Sabinum en D. 33.7.12.35. Tal opinión encontraría una prueba en el mismo comentario de Ulpiano en la frase de Sabino y Casio, anotada en la obra de Vitelio ${ }^{21}$, citada en D. 33.7.12.2722: omnia quae eo collocata sunt, ut instructior esset pater familias, instructo, inquit, continebuntur (todo lo que fue colocado para que el padre de familia estuviese más cómodo, se dice que se comprenderá en el fundo provisto o con todo aquello necesario para la producción).

Según Neracio el contenido del legado de fundo provisto con todo lo necesario para la producción (fundus instructus) sería más amplio del legado del fundo con aperos o herramentas de trabajo (fundus cum instrumento). Tal disposición habría contenido las herramientas del fundo (instrumentum fundi) y los utensilios del padre de familia (instrumentum patris familias), concediendo al legatario no sólamente un fundo con todas las herramientas necesarias para la producción sino también todos los objetos que habrían permitido al legatario la comodidad de estar en el campo así como se encontraba el testador en vida. Por lo que respecta al contenido del fundo con los aperos o herramientas para la producción (fundus cum instrumento) Neracio piensa que este concepto sería menos extenso del anterior, en un texto de Paulo, libro secundo ad Vitellium en D. 33.7.18.2. se observa como el jurista antonino excluyó ciertos bienes:

Asinam molendariam et molam negat Neratius instrumento fundi contineri.

Neracio niega la incorporación del asno utilizado en el molino así como la piedra que muele dentro de las herramientas del fundo.

qui legasset, in eo fundo habitasset, dubitari non oportere, quin et ancillae et ceterae res, quibus pater familias in eo fundo esset instructus, omnes legatae viderentur. (Uno legó a su mujer el fundo en que vivía tal y como se encontraba provisto con todo lo necesario para la producción, respecto a las esclavas que hilaban la lana se pregunta si la mismas formaban parte dentro de las herramientas del fundo, respondió que ciertamente no formaban parte de las herramientas pero como el mismo padre de familia había legado el fundo tal como se encontraba provisto con todo lo necesario para ser habitado en aquel fundo, no se debía dudar que se incluirían en el legado también todas las esclavas y las demás cosas que el padre de familia había incorporado en el fundo). Los términos consultus y respondit corresponden a Servio porque en el texto anterior en D. 33.7.16.1 Alfeno habría citado la opinión de tal jurista. En este sentido ver también Astolfi, Studi sull'oggetto dei legati in diritto romano, 2, cit., 8 ss.

${ }^{21} \mathrm{El}$ problema si Casio hubiera anotado la obra de Vitelio fue estudiado por Astolfi, Et Cassius apud ViteIlium notat, cit., 117 ss.

${ }^{22}$ Sed si fundus non sit cum instrumento legatus, sed ita ut instructus sit, quaesitum est, an plus contineatur, quam si cum instrumento legatus esset. et Sabinus libris ad Vitellium scribit fatendum esse plus 
La tesis de Neracio que excluye los asnos usados en el molino a tracción animal (o los caballos que habrían podido tener la misma función) dentro de las herramientas del fundo es contraria a la posición de la jurisprudencia anterior y posterior al jurista como se constata en un pasaje de Javoleno, libro quinto ex posterioribus Labeonis en D. 33.7.26.1:

Molas manuarias quidem suppellectilis, iumentarias autem instrumenti esse Ofilius ait. Labeo Cascellius Trebatius neutras suppellectilis, sed potius instrumenti putant esse, quod verum puto.

Ofilio afirma que los molinos manuales son seguramente considerados muebles pero los molinos en donde son usados caballos forman parte de las herramientas de trabajo (Molas-ait). Labeón, Cascelio y Trebacio piensan que ninguno de los dos tipos sea adecuado considerarlo mobiliario sino que es mejor llamarles herramientas, opinión que resulta verdadera (Labeo-puto).

Ofilio distinguía entre molinos manuales y aquellos de tracción animal (el texto se refiere a aquellos que utilizan la tracción de caballos, pero no vemos motivo para excluír los otros donde se utilizan asnos); en el primer caso los molinos eran considerados como muebles a diferencia de los segundos, porque el jurista probablemente recordaba que los molinos manuales se transportaban y los llevaban los militares al campamento ${ }^{23}$. Cascelio, Trebacio, Labeón y Javoleno no separan los dos tipos de objetos porque ellos desempeñaban la misma función y les atribuyen el significado de herramienta de trabajo (instrumentum).

En otro pasaje de Ulpiano, libro vicesimo ad Sabinum en D. 33.7.12.10 se hace notorio como en edad severiana prevalecía el pensamiento contrario a la posición de Neracio situación por la que los molinos a tracción animal y el asno usado para tal finalidad (o el caballo) habrían formado parte de las herramientas de trabajo (instrumentum):

esse, cum instructus fundus legetur, quam si cum instrumento: quam sententiam cottidie increscere et invalescere videmus. quanto igitur hoc legatum uberius est, videndum est. et Sabinus definit et Cassius apud Vitellium notat: omnia quae eo collocata sunt, ut instructior esset pater familias, instructo, inquit, continebuntur, id est quae ibi habuit, ut instructior esset. hoc ergo legato non agri instrumentum, sed proprium suum instrumentum reliquisse videtur.

${ }^{23}$ Sobre este punto ver A. Baudrillart, s.v., mola en Dictionaire des Antiquités grecques et romaines, 3, Paris, 1904, 1960 ss, y A. Wacke, Molinos y tahonas : evolución histórica y Derecho romano in Liber Amicorum J. Miquel. Estudios Romanísticos con motivo de su Emeritazgo, 2006, Barcelona, 1051 ss. 
Et molas et machinas, fenum stipulas, asinum machinarium, machinam frumentariam, vas aeneum, in quo sapa coqueretur et defrutum fiat et aqua ad bibendum lavandamque familiam paratur, instrumenti esse, et cribra, et plaustra quibus stercus evehatur.

Las herramientas de trabajo son la piedra para moler, el molino, el heno, la paja, el asno del molino, el molino del trigo, la herramienta de bronce utilizado para cocer el mosto y transformar el vino en una bebida más dulce así como el objeto en donde se proporciona agua para dar de beber a los esclavos y permitirles de lavarse, los instrumentos y los carros que sirven para transportar el guano.

Schulz ${ }^{24}$ piensa que el contenido del texto pertenece a Sabino, el cual habría afirmado su tesis en el comentario ad Vitellium ${ }^{25}$, pero, según nuestra opinión, aunque resulte evidente el análisis del argumento por el jurista, no existen pruebas de la validez de tal posición, por ese motivo preferimos ser más prudentes y limitar el contenido del pasaje a la edad severiana.

Los motivos por los que Neracio no incluyó dentro de las herramientas del fundo (instrumentum fundi) el molino y el asno a diferencia de Cascelio, Trebacio, Labeón, Javoleno y Ulpiano no son claros. Podríamos pensar que el jurista fuera de la misma posición de Alfeno ${ }^{26}$ que habría excluído los seres vivientes dentro de las herramientas de trabajo (instrumentum). Sin embargo tal pensamiento no resulta posible porque en D. 33.7.18.2 Neracio no se refiere a todos los asnos, sino únicamente al animal utilizado para moler el trigo; además, quedaría sin explicar la exclusión de la piedra del molino no obstante fuera un ser inanimado.

\footnotetext{
${ }^{24} \mathrm{~F}$. Schulz, Sabinus-Fragmente in Ulpians Sabinus-Commentar, Halle, 1906, 48 tesis aceptada por Astolfi, Studi sull'oggetto dei legati in diritto romano, 2, cit, 11 ss.

${ }^{25} \mathrm{Cfr}$. Lenel, Palingenesia luris Civilis, 2, cit, 190.

${ }^{26}$ Ulpiano, libro vicesimo ad Sabinum en D. 33.7.12.2: Alfenus autem, si quosdam ex hominibus aliis legaverit, ceteros qui in fundo fuerunt, non contineri instrumento ait, quia nihil animalis instrumenti esse opinabatur: quod non est verum: constat enim eos, qui agri gratia ibi sunt instrumento contineri. (Pero Alfeno dice que si se hubieren legado algunos esclavos no se comprenden dentro de las herramientas de trabajo los demás que existieran en el fundo, porque opinaba que ningún ser animado se comprendía dentro de las herramientas, lo que no es verdad, porque resulta notorio que los que por exigencias del campo están en él se comprenden dentro de las herramientas de trabajo). Sobre este texto ver Wacke, Molinos y tahonas: evolución histórica y Derecho romano, cit, 1075.
} 
Según Astolfi27 Neracio no incluía la figura de la herramienta de la herramienta de trabajo (instrumentum instrumenti) dentro de la idea de utensilios del fundo (instrumentum fundi), concepto en donde se incorporarían todos los objetos no destinados específicamente al mismo fundo, sino para sus herramientas de trabajo (instrumentum fundi), como por ejemplo: el personal y todos los objetos destinados a favor de los esclavos (familia rustica) ${ }^{28}$. Su tesis encontraría fundamento en un texto de Ulpiano, libro vicesimo ad Sabinum en D. 33.7.12.6.6 en donde se constata la existencia de la controversia jurisprudencial respecto a la posibilidad de incluir en el legado las herramientas de las herramientas de trabajo (instrumentum del instrumentum): sed an instrumenti instrumentum legato instrumento continetur, quaeritur.

La jurisprudencia pensaba que el asno del molino y la piedra formaban parte de las herramientas del fundo porque el trigo molido habría servido para producir pan, alimento fundamental de los esclavos ( $f a-$

\footnotetext{
${ }^{27}$ Astolfi, Studi sull'oggetto dei legati in diritto romano, 2, cit, 11 ss.

${ }^{28}$ Trebacio citado por Ulpiano, libro vicesimo ad Sabinum en D. 33.7.12.5 incluía el pistor (panadero) y el tonsor (peluquero) destinados al servicio de los esclavos, el fabrum (albañil), que reparaba la casa patronal, las mujeres dedicadas a la preparación del pan y las sirvientas de la hacienda, los molitores (molineros que molían el trigo) , la focaria y la vilica (cocinera y ama de llaves) que colaboraban junto al marido, las lanificas (tejedoras de lana) productoras de ropa destinada a los esclavos y las cocineras que preparaban platillos para ellos: Trebatius amplius etiam pistorem et tonsorem, qui familiae rusticae causa parati sunt, putat contineri, item fabrum, qui villae reficiendae causa paratus sit, et mulieres quae panem coquant quaeque villam servent: item molitores, si ad usum rusticum parati sunt: item focariam et vilicam, si modo aliquo officio virum adiuvet: item lanificas quae familiam rusticam vestiunt, et quae pulmentaria rusticis coquant. Sobre este argumento Wacke, Molinos y tahonas: evolución histórica y Derecho romano, cit, 1073 ss.

${ }^{29}$ La discusión sería afrontada por Servio como se observa al final del texto: sed an instrumenti instrumentum legato instrumento continetur, quaeritur: haec enim, quae rusticorum causa parantur, lanificae et lanae et tonsores et fullones et focariae non agri sunt instrumentum, sed instrumenti. puto igitur etiam focarium contineri: sed et lanificas et ceteros, qui supra enumerati sunt: et ita Servium respondisse auditores eius referunt. (Pero se cuestiona si en el legado del apero o utensilios se comprenden las herramientas de las herramientas, porque las que se destinan a beneficio de los esclavos que trabajan el campo como las trabajadoras de lana, los peluqueros, los lavanderos y las mujeres que cuidan la lumbre, no son herramientas del campo sino de las herramientas; opino además que también se comprenden la que cuida de la lumbre, las hilanderas y los esclavos antes citados y afirman los discípulos de Servio que así respondió el maestro) El pasaje podría estar alterado porque se repite la idea que ya había sido atribuída a Trebacio en el pasaje anterior usando los términos haec enim, quae rusticorum causa parantur, además los términos et lanae parecen fuera de lugar porque la lana no puede ser incluída entre los tipos de esclavos, por ello parece aceptable la tesis de Mommsen Ad h.I de leer et lanae tonsores. Más criticas al texto son afirmadas por Ligios, Interpretazione giuridica e realtá economica del'<<instrumentum fundi > tra il I sec. a.C. e il II sec. d.C., cit., 184 ss, con referencias bibliográficas.
} 
milia rustica) $)^{30}$; contrariamente Neracio no tenía el mismo parecer probablemente porque como tales bienes no intervenían directamente en la producción agrícola ${ }^{31}$, habría preferido incorporarlos en el concepto de fundo predispuesto con todo aquello necesario para la producción (fundus instructus).

Neracio en una carta dirigida a Aristón recordada por Ulpiano, libro trigesimo secundo ad edictum en D. 19.2.19.2, explica los objetos que el titular del fundo deberá entregar al colono para permitirle el desarrollo de su trabajo: la producción del aceite de oliva. El texto es importante en nuestra investigación porque en el elenco se encuentran identificados objetos considerados parte de los utensilios del fundo:

Illud nobis videndum est, si quis fundum locaverit, quae soleat instrumenti nomine conductori praestare, quaeque si non praestet, ex locato tenetur. et est epistula Neratii ad Aristonem dolia utique colono esse praestanda et praelum et trapetum instructa funibus, si minus, dominum instruere ea debere: sed et praelum vitiatum dominum reficere debere. quod si culpa coloni quid eorum corruptum sit, ex locato eum teneri.fiscos autem, quibus ad premendam oleam utimur, colonum sibi parare debere Neratius scripsit: quod si regulis olea prematur, et praelum et suculam et regulas et tympanum et cocleas quibus relevatur praelum dominum parare oportere. Item aenum, in quo olea calda aqua lavatur, ut cetera vasa olearia dominum praestare oportere, sicuti dolia vinaria, quae ad praesentem usum colonum picare oportebit. haec omnia sic sunt accipienda, nisi si quid aliud specialiter actum sit.

Debemos observar esto: si alguien alquiló un fundo se cuestiona sobre los objetos que normalmente forman parte de los utensilios y por los que la falta de entrega de los mismos el propietario se encontraría obligado en juicio en base a una acción (Illud-tenetur). A tal propósito existe una carta de Neracio dirigida a Aristón en donde se declara que al colono se deben dar las tinajas, la prensa y el molino para las aceitunas con las cuerdas y si no las tuviera el dueño debe proporcionarlas, pero si la prensa está defectuosa el propietario debe repararla, si contrariamente por culpa del colono alguna de estas cosas se encuentran dañada, él se encontrará obligado a responder en juicio con la acción del contrato de arrendamiento (et-teneri). Pero Neracio escribe que el colono debe proporcionarse los objetos nece-

\footnotetext{
${ }^{30}$ Catón, de Agric. 56 recuerda las raciones de alimento destinadas a los esclavos en donde el compeditus (esclavo bajo castigo) habría tenido derecho a cuatro libras de pan al dia: ...compeditis per hiemem panis pondo IIII. El pan tiene una función importante en la alimentación de los esclavos como afirma R. Etienne, Les rations alimentaires des esclaves de la <<familia rustica $\gg>$ d'après Caton en Index, 10, 1981, 66 ss. ${ }^{31}$ La fase final de la actividad productiva del fundo que produce trigo es la de molerlo como comenta Columella, De re rustica 2.20.6: ...Atque hoc supremum est aratoris emolumentum percipiendorum seminum, quae terrae crediderit.
} 
sarios que se usan para exprimir las aceitunas. Si se exprimen mediante discos, el propietario debe proporcionar la prensa, la máquina para subir y bajar pesos, los discos y las poleas con las que la prensa viene levantada; también la caldera donde las olivas vienen lavadas con el agua caliente y todos los vasos destinados al aceite, como las tinajas para el vino que el colono deberá embadurnar de una substancia hecha con pescado para hacerlas útiles (fiscos-oportebit). Todas estas cosas deben ser entendidas en estos términos a menos que no se haya establecido en modo diferente (haec-actum-sit) ${ }^{32}$.

Antes de explicar el contenido del pasaje debemos notar la existencia de una comunicación mediante carta entre Aristón y Neracio como sucede en otros textos ${ }^{33}$, pero en en el presente caso existe la particularidad que contrariamente a los existentes ${ }^{34}$, en este caso no es el pensamiento del primer jurista a ser aceptado por el segundo, sino que sucede lo contrario, es Aristón a solicitar a Neracio una opinión sobre una materia de la que parece particularmente experto, probablemente porque como provenía de una familia que producía aceite de oliva de alta calidad (oleum ex albis ulivis) ${ }^{35}$ tenía conocimiento amplio sobre el argumento.

Neracio en su carta explica las obligaciones contractuales entre el propietario del fundo y el colono ${ }^{36}$; sin embargo, el aspecto más sobresaliente en nuestra investigación consiste en el elenco de los obje-

\footnotetext{
${ }^{32}$ Eisele, Beiträge zur Erkenntniss der Digesteninterpolationen in ZSS, 10, 1889, 311 piensa que sea interpolada la última frase 'haec-actum sit', posición aceptada por Mommsen en su edición del Digesto ad h.l. n. 12; sin embargo consideramos adecuado el pensamiento de Astolfi, Studi sull'oggetto dei legati in diritto romano, 2, cit, 64, n. 185, que afirma que tal parte del texto recuerda una cláusula expresa en el contrato que podría haber sido atribuída al mismo Ulpiano.

${ }^{33}$ Como recuerda también Paulo, libro tertio quaestionum en D. 20.3.3: Aristo Neratio Prisco scripsit...y probablemente también Pomponio, libro septimo ex variis lectionibus en D. 40.4.46: Aristo Neratio Appiano rescripsit...

${ }^{34} \mathrm{Cfr}$. Lenel, Palingenesia luris Civilis, 1, cit. 61 ss. 766 ss.

${ }^{35}$ Neracio provenía de una familia de alto abolengo de Saepinum, ciudad del Sanio y como recuerda Plinio, Naturalis Historia, 15.3, el mejor aceite se producía en Italia, en la provincia de Samnium, específicamente en el territorio de Venafrum zona en donde se extraía el aceite liciano que tenía gran calidad en razón de las aceitunas de tal lugar: ...Principatum in hoc quoque bono obtinuit Italia e toto orbe, maxime agro Venafrano eiusque parte quae Licinianum fundit oleum, unde et Liciniae gloria precipua olivae... Sobre el argumento ver Italo M. Iasiello, Samnium. Assetti e trasformazioni di una provincia dell'Italia tardoantica, Bari, 2007, 70 ss.

${ }^{36}$ Corresponde a un contrato para transformar las aceitunas y no para separarlas de los árboles. Probablemente el jurista propone un modelo contractual ya en uso en las tierras de sus parientes y todavía usado por si mismo. Otras propuestas de formularios jurídicos se encuentran en Catón, De Agri cultura
} 
tos que formaban parte de las herramientas del fundo (instrumentum fundi $)^{37}$ las cuales encontrarían confirmación en otros textos literarios donde se explican los elementos necesarios para la producción del aceite de oliva en un fundo destinado a tal finalidad ${ }^{38}$ : las cubetas o vasos en forma de globo para conservar el aceite (dolia), el palo que sirve para hacer presión (praelum), la prensa con las cuerdas (trapetum instructa funibus), discos para exprimir las aceitunas (fiscos autem, quibus ad premendam oleam utimur), prensa, cuerdas, tablones, torno y poleas (praelum et suculam et regulas et tympanum et cocleas), la caldera (aenum), vasijas destinadas al aceite (vasa olearia), como por ejemplo aquellas usadas para el vino (dolia vinaria).

Neracio en D. 33.7.18.2. había excluído de los utensilios (instrumentum) el asno utilizado en el molino así como la piedra para moler pero extrañamente en D. 19.2.19.2 el jurista incorpora en el concepto

153.144 (lex oleae legendae) y 154.145 (lex oleae faciundae), pero la diferencia de contenido del segundo contrato catoniano con el neraciano no puede atribuirse a la diferencia del momento histórico, sino únicamente a aspectos que las partes tenían intención de regular.

${ }^{37} \mathrm{En}$ este sentido M. Bretone, I fondamenti del diritto romano. Le cose a la natura, Roma-Bari, 2001, 13, afirma que 'non era semplice definire l'instrumentum, e determinare il contenuto; ma era necessario offrirne un modello, perché l'interpretazione dei negozi giuridici, e della volontá che vi si manifestava, aveva bisogno di un criterio orientativo'. Debemos notar que las cosas elencadas en la carta se refieren a la transformación de la aceituna en aceite y no los utensilios necesarios para arar, podar, recoger las aceitunas del fundo. Sobre esta primera parte del proceso productivo Catón, De Agri cultura 12.10.1 explica los elementos necesarios para arreglar un olivo de 240 'yugueros': quo modo oleum, agri iugera CCXL, instruere oporteat: vilicum, vilicam, operarios quinque, bubulcos III, asinarium I, subulcum I, opilionem I: summa homines XIII. Boves trinos, asinos ornatos clitellarios qui stercus vectent tris, asinum molarium I,oves $C$. De todos modos la lista de Neracio para la producción de aceite no es completa como se observa en el pasaje de Catón citado en la nota siguiente, en el mismo sentido B.W.Frier, Law, Technology and Social Change en ZSS, 96, 1979, 208 ss, aunque no aceptamos la tesis del investigador en p.212 ss, que afirma que los utensilios para exprimir las aceitunas recordados por Neracio no corresponden a su momento histórico, porque si bien tales objetos son recordados por Catón, De Agri cultura 12.10.2, los mismos encontrarán todavía uso en edad antonina para obtener aceite según un método tradicional. Una propuesta para su preparación se encuentra en Columela, De re rustica, 12.52.10

${ }^{38}$ Catón, De Agri cultura 12.10 .2 en referencia al mismo olivar de 240 'yugueros': 5 vasijas para elaborar el aceite y demás accessorios (vasa olearia instructa iuga quinque), una caldera de la capacidad de 30 'cuadrantalia' y su tapadera (henum quod capiat quadrantalia XXX, operculum aheni), 3 'uncinos' de hierro (uncos ferreos III), 3 brocas para el agua (urceos aquarios III),2 embudos (infidibula II), una caldera de la capacidad de 5 'cuadrantales' (ahenum quod capiat quadrantalia V), 3 garfios no metálicos (uncos III), una cubeta pequeña (labellum pollulum I), 2 ánforas para aceite (amphoras olearias II), una urna de 50 'eminas' (urnam quinquagenariam unam), 3 cacerolas (trullas tris), una cubeta para el agua (situlum aquarium I), un contenedor de metal (pelvim I), un vaso (matellionem), una vasinica (trullium), un pequeño sartén (scutriscum), un vaso de forma diferente al anterior (matellam), una regadera (nassiternam), un bracero (trullam), un candelabro (candelabrum), un recipiente de medio litro (sextarium)... Los otros elementos del texto no los citamos porque no corresponden específicamente a la transformación de las aceitunas en aceite. Sobre 
de utensilios elementos que sirven para la misma función: moler o aplastar. La razón de tal diferencia podría ser explicada en el resultado final de la producción, en el primer caso, después de molerse el grano para transformarlo en harina se llevaba para vender como recuerda Varrón, De re rustica, 1.53: messi facta, spicilegium venire oportet..., en el segundo, después de separar las aceitunas del árbol no se terminaba el proceso de producción, sino que se requería un paso siguiente que consistía en transformarlas en aceite de oliva, como demuestra Catón, De Agri cultura 12, cuando explica que entre los utensilios necesarios para arreglar un plantío de olivos de 240 'yugueros' incluye objetos necesarios para la transformación de las aceitunas en aceite.

Hemos visto anteriormente como Neracio en D. 33.7.12.35 incorporaba en el fundo provisto con todo aquello necesario para la producción (fundus instructus) los esclavos (mancipia), no solo los que tienen la función de cultivar o cuidar la casa patronal sino también los que se encuentran al servicio personal del pater familias: mancipia non solum ad cultum custodiamve villae, sed etiam quae ut ipsi patri familias in ministerio ibi essent. Los términos non solum y sed etiam demuestran, según nosotros, como el jurista, en la determinación del contenido del fundo instruido con los elementos necesarios para la producción (fundus instructus) tuviera en mente no únicamente los esclavos incorporados dentro de las herramientas del fundo (instrumentum fundi), sino también otros con una actividad diferente. Tal constatación nos permite suponer que según Neracio, los esclavos (mancipia), para poder ser incorporados en el concepto de utensilios (instrumentum) deberían haber desarrollado alguna de estas dos funciones: cultivar la tierra o cuidar el casco de la hacienda.

En referencia al fundo provisto con los elementos necesarios para la producción (fundus instructus) encontramos diferentes tipos de esclavos que tienen como función cuidar la casa patronal y dentro de ellos citamos al saltuarius, esclavo que tenía la función de vigilar el fundo o gardabosques. En referencia a tal figura Ulpiano, libro vicesimo ad Sabinum en D. 33.7.12.4 recuerda las posiciones jurispruden-

el argumento ver H. Blümner, Tecnologie und Terminologie der Gewerbe und Künste bei Griechen und Römern, 1, Leipzig-Berlin, 1912, 610 ss., M. Besnier, s.v. olea, oleum en Dictionnaire des Antiquités Grecques et Romaines, 4.1, Paris, 1877, 162 ss, A.G. Drachmann, Ancient Oil Mills and Presses, Kobenhavn, 1932, 1 ss, los autores citados por Bretone, I fondamenti del diritto romano. Le cose a la natura, cit., 243, pero sobretodo la bibliografía de A. Browman e A. Wilson, Olive Oil Production and Trade Bibliography en The Oxford Roman Economy Project, Oxford, fácilmente consultable en internet. 
ciales en la determinación de sus funciones para poderlo considerar dentro de la noción de herramientas del fundo (instrumentum):

Saltuarium autem Labeo quidem putat eum demum contineri, qui fructuum servandorum gratia paratus sit, eum non, qui finium custodiendorum causa: sed Neratius etiam hunc, et hoc iure utimur, ut omnes saltuarii contineantur.

Según Labeón el saltuarius formaba parte de las herramientas del fundo (instrumentum) únicamente si se le hubiera asignado el trabajo de la vigilancia de los frutos pero no la de los confines del fundo; sin embargo Neracio incluye en el concepto también los que tienen la segunda función. En la actualidad es aceptada la segunda posición en modo que los saltuarii resulten incorporados dentro de las herramientas de trabajo.

Evidentemente el saltuarius no participa en la actividad productiva del fundo pero Labeón, dándose cuenta de la importancia de vigilar los frutos incluirá el esclavo encargado de tal función dentro del concepto de herramientas del fundo (instrumentum), para evitar así el robo de los frutos cultivados. Neracio será todavía mayormente atento porque en la agricultura intensiva la vigilancia no se puede limitar únicamente al fruto sino que deberá incluir también la tierra donde la semilla germina. Los términos eum non, qui finium custodiendorum causa del pasaje parecerían ser atribuídos a Labeón pero según nosotros, es posible una segunda interpretación: Ulpiano habría incorporado tal frase para destacar la evolución del pensamiento de Labeón en edad antonina, así, bajo tal perspectiva, la tesis neraciana no sería en contradicción con la anterior sino simplemente la ampliaría.

Otro problema en relación al legado del fundo con herramientas de trabajo (cum instrumento) afrontado por Neracio es recordado por Paulo, libro tertio ad Neratium en D. 33.7.24.

Fundus,qui locatus erat, legatus est cum instrumento: instrumentum, quod colonus in eo habuit, legato cedit. Paulus: an quod coloni fuit an tantum id quod testatoris fuit? et hoc magis dicendum est, nisi nullum domini fuit.

El fundo que se encontraba alquilado fue legado con las herramientas (Fundus-instrumento): las herramientas que el colono tenía en el fundo cede al legado (instrumentum-cedit). Paulo sobre tal afirmación 
se pregunta si las herramientas eran del colono o si únicamente pertenecían al testador (Paulus-fuit). Y esta tesis deberá ser sostenida sobretodo si nada hubiera pertenecido al propietario (et-fuit).

El testador deja en legado un fundo con las herramientas de trabajo (fundus cum instrumento) alquilado a un colono ${ }^{39}$ y según Neracio las herramientas usadas por el colono para trabajar el fundo se considerarán parte del legado. Esta posición ciertamente podría parecer extraña porque existiendo un contrato de locatio conductio, el titular del fundo no se convertiría en propietario de las herramientas de trabajo del colono. Sin embargo, debemos recordar la facultad del propietario del fundo en base al contrato establecido de tomar en prenda las cosas de la persona que alquila para garantizar los pagos del alquiler ${ }^{40}$; por esto, según nuestra opinión, la afirmación del jurista se debería interpretar en el sentido que, así como el testador habría tenido derecho a la posesión de las herramientas de trabajo en el caso en que no hubiera sido pagado el alquiler, también el legatario habría tenido el mismo derecho del de cuius en base al contrato (legato cedit).

Además Paulo recuerda que los utensilios usados por el colono para trabajar la tierra no necesariamente deberían ser del colono sino del propietario del fundo, esto indica claramente la aplicación de la tesis neraciana en el primer caso ya que en el segundo la solución habría sido evidente ${ }^{41}$.

\section{Casa amueblada (Domus instructa)}

Después de haber afrontado el estudio del fundo provisto con todo aquello necesario para la producción (fundus instructus) y el fundo con los aperos o herramientas de trabajo (fundus cum instrumento),

\footnotetext{
${ }^{39}$ Sobre la relación entre el propietario del fundo y el colono ver Columela, De re rustica, 1.7 y la doctrina citada por G. Giliberti, Servi della terra. Ricerche per una storia del colonato, Torino, 1999, 1 ss.

${ }^{40} \mathrm{Gayo}, 4.147$ tratando del edicto salviano recuerda una cláusula del contrato en donde el colono acordaba que se encontrarían en prenda sus cosas para el pago del alquiler del fundo: interdictum quoque, quod appellatur Salvianum, adipiscendae possessionis causa comparatum est, eoque utitur dominus fundi de rebus coloni, quas is pro mercedibus fundi pignori futuras pepigisset. Sobre el argumento ver O. Lenel, Das Edictum perpetuum, Aalen, 1956, 490 ss.

${ }^{41}$ Diferentemente Astolfi, Studi sull'oggetto dei legati in diritto romano, 2, cit, $31 \mathrm{ss,} \mathrm{interpreta} \mathrm{el} \mathrm{texto}$ en el sentido que Paulo era contrario a la posición de Neracio pero no vemos una razón para aceptar su tesis. El pasaje fue analizado por Voci, Diritto ereditario romano, 2, cit. 280 y Giliberti, Servi della terra. Ricerche per una storia del colonato, cit. 106 ss.
} 
resulta más facil entender el contenido del legado de casa amueblada (domus instructa) en el pensamiento de Neracio. La posición del jurista viene confirmada en un pasaje de Ulpiano, libro vicesimo ad Sabinum en D.33.7.12.43, donde se recuerda una carta dirigida a su hermano en donde opina sobre tal cuestión:

Idem respondit (Papiniano) domo instructa legata mensas eboreas et libros non contineri: sed et hoc falsum est: nam omne, quidquid in domo fuit, quo instructior ibi esser pater familias, continebitur, suppellectilem autem patris familiae instrumentum esse nemo dubitat. denique Neratius libro quarto epistularum Marcello fratri suo respondit et vestem domus instructae legato contineri:maxime, inquit, in proposita specie: proponebatur enim, qui legaverat, argentum et rationes excepisse: nam qui haec, inquit, excepit, non potest non videri de ceteris rebus, quae in ea essent, sensisse. sed et ipse Papinianus eodem libro responsorum ait patrem mercatorem ac faeneratorem, qui duos filios totidemque filias heredes instituerat, ita legasse: 'filiis maribus domum meam instructam do lego darique iubeo': merces et pignora an contineantur, quaeri posse: sed facilem iudici voluntatis coniecturam fore ceteris patris facultatibus examinatis.

Además respondió Papiniano que en la casa amueblada dada en legado no son incluídas las mesas de marfil y tampoco los libros; pero esto es falso según Ulpiano, ya que es contenido todo aquello que se encuentra en la casa a disposición del pater familias, por otra parte nadie tiene dudas que las cosas muebles forman parte de los objetos destinados a beneficio del pater familias (Idem-dubitat). Además Neracio, en el libro cuarto de sus epístulas, respondió a su hermano Marcelo que en la casa amueblada dada en legado se comprendia también la ropa, sobretodo en el caso específico se dijo que se excluían en el legado la plata y las cuentas. Haciéndose en este modo el testador excluía algunos objetos de manera que no se pudiera pensar en modo diferente, considerándose incluídos por esto todos los demás objetos que se encontraban en la casa (denique-sensisse). Pero Papiniano en el mismo libro de sus epístolas presenta un problema: si el pater comerciante o un banquero hubieran instituído herederos a sus dos hijos e hijas legando en este modo "concedo en legado y doy y ordeno a mis hijos de género masculino la casa amueblada'. El jurista se cuestiona si estarían incluidas la mercancia y los créditos, afirmando que será facil para el juez interpretar la voluntad examinando las demás disposiciones del pater (sed-examinatis).

Ulpiano recuerda la tesis de Papiniano del libro séptimo responsorum ${ }^{42}$

\footnotetext{
${ }^{42}$ Ulpiano inicia la citación a la obra de Papiniano en D. 33.7.12.23: Papinianus quoque libro septimo responsorum ait..., después continua en los párrafos 37-43 y 45-47 confront. Lenel, Palingenesia, cit., 1,
} 
en donde había negado incluir las mesas de marfil y los libros en el legado de casa amueblada (domus instructa). Como hemos visto anteriormente en el concepto de muebles existía una controversia jurisprudencial entre Celso, Pomponio y Paulo respecto al hecho de incluir objetos hechos de materiales preciados. Según el primer jurista citado, reconociendo las costumbres de la nobilitas romana de su periodo histórico, en donde existia un mayor interés por el lujo, consideraba tal posibilidad (D. 33.10.7.1); Pomponio era contrario (D. 33.10.1) mientras que Paulo aceptaba la posición de Celso (D. 33.10.3 e 5). Como el marfil era un material preciado ${ }^{43}$, parecería evidente que Papiniano aceptase la tesis de Pomponio, mientras que Ulpiano habría estado de acuerdo con Celso y Paolo.

Papiniano habría negado incluir las mesas de marfil en el legado de casa amueblada (domus instructa) ya que a su parecer tales objetos no formaban parte del concepto de muebles y la misma razón explicaría porqué el jurista no incluyó los libros en el legado de casa amueblada (domus instructa) ${ }^{44}$ por lo que para el jurista el concepto de casa amueblada (domus instructa) significaba simplemente la cosa principal y los muebles excluyendo las cosas preciadas ${ }^{45}$. Ulpiano no era de la misma opinión (sed et hoc falsum est), porque los materiales preciados serían considerados parte de los utensilios y si bien es cierto los muebles no incluían los libros, la casa amueblada (domus instructa) los habría incluido ya que se encontraban dentro de la demora a disposición del pater familias (nam omne, quidquid in domo fuit, quo instructior ibi esser pater familias, continebitur) al mismo modo de los demás utensilios del pater familias denominados supellex (suppellectilem autem patris familiae instrumentum esse nemo dubitat).

\footnotetext{
${ }^{43} Y a$ en los tiempos de Plinio el viejo el marfil en Roma se había convertido en material muy raro por causa del excesivo lujo como recuerda en Naturalis historia 8.4: ...etenim rara amplitudo iam dentium praeterquam ex India reperitur; cetera in nostro urbe cessere luxuriae. Sobre este argumento ver A. Jacob, s.v. ebur en Dictionnaire des Antiquités Grecques et Romaines, 2.1, Paris, 1892, 444 ss.

${ }^{44}$ También Paulo, libro quarto ad Sabinum en D. 33.10.3.2 excluye los libros del concepto de muebles así como las cajas y los armarios en donde se encontraran colocados: ...sed sunt qui recte putant capsas et armaria, si librorum ...parata sint, non esse in suppellectili, quia ne hae quidem ipsae res, quibus adtributae essent, suppellectilis instrumento cederent.

${ }^{45} \mathrm{El}$ mismo criterio se encuentra aplicado por Papiniano cuando trata del fundo provisto con todo lo necesario para la producción (fundus instructus). El jurista en la misma obra en D. 33.7.12.46 analiza una propuesta de interpretación de la voluntad del testador, el cual, además de conceder en legado el fundo provisto con todo lo necesario para la producción ( fundus instructus) habría incorporado además a la disposición la frase 'con todos los muebles, esclavos, o con una sola cosa, que determinadamente no había sido expresada (cum supellectili vel mancipis vel una aliqua re, quae nominatim espressa non erat)' concluyendo Papiniano: no se considera disminuido sino más bien aumentado por redundancia el concepto (non videri minutum, sed potius ex abundanti adiectum).
} 
Después de las afirmaciones de Papiniano, en el texto se incluye el contenido de la famosa carta de Neracio escrita a su hermano Marce$1 \mathrm{l}^{46}$, el cual le habría cuestionado al jurista sobre el contenido del legado de casa amueblada (domus instructa). No sabemos si el hermano era el heredero, el legatario o si el caso se refería a un amigo, pero de la referencia de Ulpiano la pregunta se presenta en este modo: el testador había dejado en legado una casa amueblada (domus instructa) excluyendo la plata y las cuentas. La cuestión que emerge del pasaje consistía en determinar si la ropa formaba parte del legado. Para continuar el análisis del texto debemos recordar el pensamiento de Neracio en D. 33.7.12.35 en relación al fundo provisto con todo lo necesario para la producción (fundus instructus). El jurista elencaba sobretodo los elementos existentes en la casa patronal y debido a que la diferencia con la domus era mínima (la prima se encontraba en el campo mientras que la segunda en la ciudad), no creemos que existan obstáculos para aplicar las conclusiones anteriores a la casa amueblada (domus instructa). Por lo tanto entre los objetos incorporados a la casa deberíamos incluir los muebles, los vinos y los esclavos, no únicamente los destinados a la custodia de la casa sino también al cuidado del mismo pater familias; además se incluían todos los objetos pertenecientes al testador cuando todavía se encontraba en vida que habrían servido para su comodidad como por ejemplo, según nuestra opinión, los libros y los armarios en donde se colocaban. Como se podría pensar, la respuesta del jurista habría sido a favor porque, si este tipo de legado incluía todo aquello que se encontraba en la casa (de ceteris rebus, quae in ea essent) evidentemente también la ropa habría formado parte del legado. La solución de Neracio no cambia en el caso de exclusión de la plata y de las cuentas (argentum et rationes excepisse) de la casa amueblada (domus instructa) por parte del testador, sino que refuerza su posición (maxime).

Tratando el argumento del fundo provisto con todo lo necesario para la producción (fundus instructus) hicimos notar como parte de la jurisprudencia habría incluido en el concepto de mobiliario objetos de alto valor, sin haber establecido si Neracio aceptaba o no tal posición. Si

\footnotetext{
${ }^{46} \mathrm{M}$. (Hirrius) L. Neratius Marcellus nació alrededor del 62 d.C, hermano de Neracio Prisco, cónsul en el año 95 d.C. por primera vez, legado imperial de Britania en enero del año 103 d.C y cónsul en el año 129 d.C. por la segunda vez, citado por Plinio, ep. 3.8.1, tuvo como padre adoptivo M. Hirrius Fronto Neratius Pansa. Su hijo fue probablemente el cónsul L. Neratius Corellius Pansa del 122 d.C. Sobre este argumento ver Camodeca, La carriera del giurista L. Neratius Priscus, cit., 32 ss. Posición confirmada por el mismo autor en II giurista L.Neratius Priscus Cos. Suff. 97 nuovi dati su carriera e famiglia, cit., 299 e 311 y L. Vidman, s.v. L. Neratius Marcellus en Prosopographia imperii romani, 5.3, Berolini, 1987, 342 ss.
} 
hubiera sido de tal opinión (parecería que si porque en caso contrario Ulpiano habría debido destacar que era contrario al pensamiento de Neracio visto que había transcrito parte del contenido de la carta), surge una cuestión no explicada en el pasaje: ¿Los objetos de plata destinados al uso del pater familias habrían sido excluídos del legado o formarían parte del mismo? Según nuestra opinión Neracio habría sido de la segunda opinión porque si para el jurista la casa amueblada (domus instructa) incluía (así como el fundo provisto con todos los elementos necesarios para la producción) todos los objetos considerados como muebles que permitían al legatario la facultad de permanecer en manera cómoda como lo había hecho el testador en vida, esto habría significado una predisposición a considerar también los utensilios personales de plata en este tipo de legado como por ejemplo aquellos destinados a comer y beber (Argentum escarium et potorium ${ }^{47}$ ).

Según Neracio el legado de casa amueblada (domus instructa) habría debido incluír la ropa existente en la casa pero, según nuestra opinión, si la misma hubiera contenido hilos de plata o botones de este material, el metal se consideraría parte de la cosa principal como recuerda Ulpiano, libro vicesimo ad Sabinum en D. 34.2.19.5 en un caso parecido: (los botones de oro y la púrpura -un tinte de altísimo valor- son parte de los vestidos: ...clavi aurei et purpurae pars sunt vestimentorum). Tales consideraciones nos harían pensar al supuesto de que el testador, si bien hubiera excluído la plata en el legado de casa amueblada (domus instructa), el legatario habría tenido la posibilidad de obtener objetos de plata como en ciertos casos específicos discutidos anteriormente.

Sobre este aspecto debemos determinar el tipo de plata ${ }^{48}$ excluído

\footnotetext{
${ }^{47}$ Como habría considerado Paulo, libro quarto ad Sabinum en D. 33.10.3.3: Vitrea escaria et potoria in supellectili sunt...nam et pelves argenteas et aquiminalia argentae...argentea et mensas et...in supellectili esse non dubitatur... ( Los objetos de vidrio para comer y beber se comprenden dentro del concepto de utensilios...ciertamente los contenedores de plata y las jarras de plata...y las mesas de plata son consideradas parte del mobiliario).

${ }^{48}$ Neracio no explica el tipo de plata excluído en el legado como sucede en el pasaje de Ulpiano presentado en seguida. Las fuentes refieren la existencia de argentum escarium et potorium (vajilla de plata) y el argentum factum (plata cincelada) definido por Ulpiano, libro quadragesimo quarto ad Sabinum en D. 34.2.27.6 como la plata que no se encuentra en pasta, ni en láminas, ni acuñada y que no forma parte del mobiliario, ni de los objetos del baño o de adorno: argentum factum recte quis ita definierit, quod neque in massa neque in lamna, neque in signato neque in supellectili neque in mundo neque in ornamentis insit. El argentum infectum (no trabajado) citado por Ulpiano, libro vicesimo ad Sabi-
} 
por el legado según la voluntad del testador. En el caso afrontado probablemente se refería al metal precioso que se encontraba en la casa pero que no formaba parte del mobiliario de la casa amueblada (domus instructa); esto es, la plata claramente identificable como tal, por ejemplo, la colocada en un baúl que tuviera esta función (el argentarium), como recuerda Ulpiano, libro vicesimo ad Sabinum en D. 34.2.19.8:

Lectum plane argenteum vel si qua alia supellex argentea fuit, argenti appellatione non continetur, si numero argenti habita non est, ut in iunctura argentea scio me dixisse, quod non in argentario pater familias reponebat. sed nec candelabra nec lucernae argenteae vel sigilla, quae in domo reposita sunt, vel imagines argenteae argenti appellatione continebuntur, nec speculum vel parieti adfixum vel etiam quod mulier mundi causa habuit, si modo non in argenti numero habita sunt.

Ciertamente en el concepto de plata no se incluye la cama de plata y tampoco las cosas plateadas consideradas como mobiliario siempre que no sea indicadado el contrario, como recuerdo haber dicho en el caso de la decoración hecha de plata, porque el pater familias no la había colocado en el baúl destinado a la plata (Lectum-reponebat). No son incluídos en el concepto de plata los candelabros, las lámparas de plata y las pequeñas esculturas que hayan sido puestas en la casa o los retratos enmarcados en plata (sed nec-continebuntur), ni el espejo inclusive el colocado en la pared y tampoco el que pertenece a los objetos personales de la mujer si no se declara expresamente (ne speculum-habita sunt).

Relacionando el presente pasaje con la carta de Neracio podríamos pensar que si el testador hubiera tenido en su casa un baúl en donde hubieran sido colocados objetos de plata, la exclusión de la plata en el legado de la casa amueblada (domus instructa) habría significado la imposibilidad del legatario de pretender los objetos de plata

\footnotetext{
num en D. 34.2.19.pr. formaría parte del legado de plata junto al cincelado factum: cum...argentum legatum est...legato continetur sive factum sive infectum. El argentum fractum vel collisum (pedacería de plata) no se encontraría considerado dentro del argentum infectum (plata no trabajada) como había afirmado Servio, citado por Ulpiano, libro quadragesimo quarto ad Sabinum en D. 34.2.27.3: cui aurum vel argentum factum legatum est, si fractum aut collisum sit, non continetur: Servius enim existimat aurum vel argentum factum id videri, quo commode uti possumus, argentum autem fractum et collisum non incidere in eam definitionem, sed infecto contineri. (Si a uno se le legó el oro o la plata labrada no se comprende la misma si fuera la pedacería porque opina Servio que se considera oro o plata labrada aquella que podemos usar cómodamente, pero la pedacería no entra en esta definición sino que se considerará dentro de la que está sin labrar). La plata a la que habría hecho referencia Neracio era evidentemente la trabajada y la no labrada (factum e infectum).
} 
conservados en el baúl (argentarium), pero no los otros del mismo metal incluídos en el concepto de mobiliario explicados por Ulpiano. La situación habría sido diferente si hubiera faltado el baúl destinado a la plata (el argentarium) como recuerda Astolfifi, porque las condiciones económicas del testador, la clase social a la que pertenecía y sus costumbres de vida habrían sido tales que habría usado el mobiliario de plata en casos excepcionales.

Quisieramos por último destacar el modo de razonar de Neracio en la determinación del contenido del legado en la presente materia: si el testador hubiera excluído en el legado objetos que se encontraban en la casa, todos los demás habrían sido considerados parte de la casa amueblada domus instructa (nam qui haec, inquit, excepit, non potest non videri de ceteris rebus, quae in ea essent, sensisse). Tal criterio se podría aplicar, según nosotros, a todos los casos análogos como el fundus instructus y la taberna instructa.

Después de haber mencionado la carta de Neracio, Ulpiano introduce otro problema afrontado por Papiniano en el mismo libro de sus responsos, en donde el pater habría tenido la profesión de comerciante o banquero. Debido a que el jurista inicia con una palabra que tiene el significado de oposición (sed), parecería que tal particularidad no hubiera existido en el caso anterior. Sobre este aspecto sólamente quisieramos decir que Papiniano en la determinación del legado de la casa amueblada (domus instructa) tomó en consideración el contenido del testamento en su integridad para determinar en este modo la efectiva voluntad del de cuius sobre la problemática objeto de análisis.

\section{Utensilios de un negocio (Instrumentum tabernae)}

El término taberna en origen tenía el significado de construcción de cualquier tipo idóneo para ser habitado o un lugar cerrado con tablas como recuerda Ulpiano, libro vicensimo septimo ad edictum en D. 50.16.183: 'Tabernae' appellatio declarat omne utile ad habitandum aedificium, non ex eo quod tabulis cluditur. La palabra se transforma en edad clásica para considerar la sede de diferentes actividades comerciales, alimentarias, artesanales, profesionales o de servicios ${ }^{50}$.

\footnotetext{
${ }^{49}$ Astolfi, Studi sull'oggetto dei legati in diritto romano, 2, cit, 171.

${ }^{50}$ Por ejemplo Escévola, libro tertio responsorum en D. 31.88 .3 recuerda la taberna ferraria (ferretería), Ulpiano, libro quadragesimo quarto ad Sabinum en D. 18.1.32, la taberna argentaria (banco y
} 
En los incisos anteriores resulta evidente como en el legado de fundo provisto con todos los elementos necesarios para la producción (fundus instructus) y en la casa amueblada (domus instructa) se encontraba incorporado el lugar en donde venía desarrollada la actividad agrícola o donde se vivía; por esto, al mismo modo, en el legado de negocio con todos los elementos necesarios para desarrollar la actividad (taberna instructa) se debería incluir el lugar en donde venía ejercitada la actividad comercial, como también todos los objetos y esclavos necesarios para su desarrollo ${ }^{51}$. Según las conclusiones anteriores, cuando existiera duda sobre la inclusión de un determinado objeto en este tipo de legado, según Neracio habría sido aplicado analógicamente el criterio enunciado en D.33.7.12.43: nam qui haec, inquit, excepit, non potest non videri de ceteris rebus, quae in ea essent, sensisse (ciertamente el que exceptuó estas cosas no puede no ser considerado como habiéndose referido a las demás cosas que hubiese en ella).

El jurista antonino explica sobretodo el significado del instrumentum tabernae en el segundo libro de sus responsos en D. 33.7.23:

Cum quaeratur, quod sit tabernae instrumentum, interesse, quod genus negotiationis in ea exerceri solitum sit.

Cuando exista la discusión de cuales son los utensilios de un negocio es importante conocer cual tipo de actividad comercial se ejercita en este.

Neracio justamente observa como en la determinación de los utensilios de un negocio sea necesario (interesse) conocer la actividad comercial de la misma. Por ello en una taberna popina (fonda) son in-

venta de objetos de plata), Pomponio, libro singulari enchiridii en D. 1.2.24, la taberna lanionis (carne y lana), Aristón en la referencia de Ulpiano, libro septimo decimo ad edictum en D. 8.5.8.5 la taberna casiaria (negocio de lácteos), Papiniano, libro septimo responsorum en D. 32.91.2 la taberna purpuraria (negocio de la púrpura un colorante muy caro y fino).

${ }^{51} \mathrm{El}$ significado de negocio con todos los elementos necesarios para desarrollar la actividad (taberna instructa) es explicado por Ulpiano, libro vicensimo octavo ad edictum en D. 50.16.185: 'Instructam' autem tabernam sic accipiemus, quae et rebus et hominibus ad negotiationem paratis constat. (Pero entenderemos provista de todos los elementos necesarios para desarrollar la actividad el negocio que conste de cosas y de hombres dedicados a la actividad comercial). P. Cerami en Lezioni di Diritto Commerciale Romano, Torino, 2002, 51 ss., traduce el texto en este modo: 'assumiamo invero l'azienda come un complesso di beni ed uomini organizzati per l'esercizio dell'impresa'. Sobre este argumento ver por último A. Campanella, Brevi riflessioni su D. 50.16 .185 (Ulp., 28 ad ed.). Profili terminologicoconcettuali della definizione ulpianea di taberna instructa e locuzioni sostanzialmente equivalenti nella riflessione giurisprudenziale romana tra il I sec. a.C. e il III d.C. en Diritto @ Storia, 8, 2009, 1 ss. 
cluídos la cocta (olla para alimentos cocidos), la calda (calderón para el agua caliente), mientras que en la taberna vinaria (bar) los armarios (armaria), las mesas (tabulae o mensae) y las sillas (sellae). Específicamente en la taberna cauponia (hotel) el jurista considera los institores (esclavos que trabajan en la actividad comercial) como parte de los elementos (instrumentum) de la misma como recuerda Paulo, libro quarto ad Sabinum en D. 33.7.13 pr.-1:

Tabernae cauponiae instrumento legato etiam institores contineri Neratius existimat: sed videndum ne inter instrumentum tabernae cauponiae et instrumentum cauponae sit discrimen, ut tabernae non nisi loci instrumenta sint, ut dolia vasa ancones calices trullae, quae circa cenam solent traici, item urnae aereae et congiaria sextaria et similia: cauponae autem, cum negotiationis nomen sit, etiam institores. 1. Instrumento balneario legato etiam balneatorem contineri Neratius respondit.

Según Neracio ${ }^{52}$, en el legado de los utensilios del hotel se incluían los esclavos dedicados a tal actividad o institores (Tabernaeexistimat). Pero debería ser observado si no exista diferencia entre los utensilios del hotel en sí y los que comprenden toda su actividad desde el punto de vista comercial, ya que entran dentro de los utensilios del hotel en sí los botes, los vasos, las botellas, las copas, las cucharas usadas para servir la cena, además de vasijas de cobre de la mitad de una ánfora, recipientes de tres litros y un cuarto, de medio litro y demás (sed-similia). Diferentemente dentro de los utensilios del hotel entendido como negocio de hotelería se encuentran incluídos también los esclavos que trabajan o institores (cauponae-institores). Además Neracio respondió que en el legado de utensilios de una actividad dedicada a los servicios de baños se encuentran comprendidos también los esclavos que ayudan en tal actividad.

Quisieramos destacar como en el pensamiento de Neracio dentro de los utensilios del negocio (taberna) se encontraba incluído el personal ${ }^{53}$ al mismo modo como había hecho en el caso de los utensilios del fundo (instrumentum fundi), por ejemplo en D. 33.7.12.4 incorpo-

\footnotetext{
${ }^{52}$ Probablemente en el libro segundo de sus responsos. En este sentido Lenel, Palingenesia luris Civilis, 1, cit. 776.

${ }^{53}$ Opinión afirmada anteriormente por Servio y aceptada por la jurisprudencia posterior, así recuerda Pomponio, libro sexto ad Sabinum en D. 33.7.15 pr. en donde el testador deja en legado un molino y un hotel y sin usar la palabra utensilios (instrumentum), utiliza terminología que se asimilaría a tal concepto: si ita testamento scriptum sit: 'quae tabernarum exercendarum instruendarum pistrini cauponae causa facta parataque sunt, do lego', his verbis Servius respondit et caballos, qui in pistrinis essent, et pistores, et in cauponio institores et focariam, mercesque, quae in his tabernis essent, legatas videri (Si se hubiera escrito así en el testamento: 'doy y lego las cosas que se hicieron y prepararon para la explotación y provisión del molino y del hotel' respondió Servio, que con estas palabras se considera
} 
raba el saltuarius que debía vigilar los confines del fundo). Paulo ${ }^{54}$ contrariamente prefiere distinguir entre utensilios (instrumentum) del establecimiento donde se encuentra el hotel y los utensilios de la empresa hotelera; en el primer caso habrían sido excluídos los institores contrariamente al segundo. Evidentemente para Neracio los utensilios (instrumentum) del hotel (taberna cauponia) coincidía con todos los elementos de la empresa hotelera en su complejidad y no únicamente en relación al lugar; por esto el legatario, según el jurista, habría obtenido todos los objetos destinados al negocio (negotiatio) como eran los institores, esclavos que trabajaban en ese lugar.

Recordando la diferencia entre el legado del fundo provisto con todos los elementos necesarios para la producción (fundus instructus) y el de los utensilios del fundo (instrumentum fundi) surge la cuestión de la razón por la cual Neracio en D. 33.7.13 pr. trató del legado de los utensilios (instrumentum) del hotel (taberna cauponia) y no del hotel predispuesto con todo lo necesario para su actividad (taberna instructa), visto que en el texto parecería existir la intención del testador de transmitir al beneficiario el negocio hotelero en su complejidad y no solo conceder los objetos y los esclavos destinados a la actividad comercial. Probablemente el de cuius no era el propietario del lugar en donde se encontraba el hotel (taberna) sino únicamente de los esclavos y los objetos necesarios para permitir la actividad hotelera, situación por la que su intención habría sido la de transmitir los utensilios (instrumentum) al legatario para permitir la continuación de la actividad empresarial ${ }^{55}$.

que se legaron también las caballerías que hubiera en los molinos y los molineros y en los hoteles sus encargados, la que cuida la lumbre y las mercancías que se encontraran ahí).

${ }^{54}$ Cerami, Lezioni di diritto commerciale romano, cit., 55 no acepta la posición de Ligios, $<<$ Taberna $>>$, $<<$ negotiatio $>>,<<$ taberna cum instrumento $>>e<<$ taberna instructa $>>$ nella riflessione giurisprudenziale classica, 79 ss. en el sentido que las palabras sed videndum (atribuídas a Paulo) demuestran una posición diferente del jurista severiano a la tesis neraciana, la palabra sed no tiene un valor de contrariedad y de corrección, según el investigador, sino de explicación y para dar fuerza a la idea; así 'Paolo avrebbe soltanto precisato che per cogliere e valutare il significato e le implicazioni pratiche del rinvio neraziano al genus negotiationis occorreva distinguere fra taberna, intesa come puro e semplice locale e taberna instructa, intesa come azienda'. La posición del investigador es aceptable, si bien, como veremos más adelante, el testador no habría sido el titular del lugar sino únicamente de los utensilios del negocio. La distinción de Paulo no llegó en Pauli Sententiae 3.6.61: instrumento cauponio legato ea debentur, quae cauponis usui parata sunt, velut vasa, in quibus vinum defunditur: escarai quoque et pocularia vasa debentur.Sane ministri earum rerum legato non cedunt. Sobre este problema ver Astolfi, Studi sull'oggetto dei legati in diritto romano, 2, cit. 31 el cual acepta la reconstrucción del pensamiento de Paulo propuesto por Voci, Diritto ereditario romano, 2, cit. 278 ss.

${ }^{55} \mathrm{El}$ negocio comercial (taberna) podía ser establecida en suelo público como puede constatarse en el 
En el caso del legado de utensilios (instrumentum) de un balneario o usando términos modernos una 'SPA' (balnea meritoria $)^{56}$, al mismo modo que los otros tipos de legados, se encontraban incluídos los esclavos que desempeñaban actividades en el lugar no solamente administrativas sino también materiales como por ejemplo razgar con lo strigilis ${ }^{57}$ los cuerpos de los clientes y llevar el linteum (toalla ${ }^{58}$. Sobre este punto también el jurista Marciano, libro septimo institutionum en D. 33.7.17.2 incluye los esclavos del balneario dentro del concepto de utensilios:

Instrumento balneatorio legato dictum est balneatorem sic instrumento contineri balneario, quomodo instrumento fundi saltuarium et topiarios, et instrumento cauponio institorem, cum balneae sine balneatoribus usum suum praebere non possint.

pasaje de Ulpiano, libro quadragesimo quarto ad Sabinum en D. 18.1.32: qui tabernas argentarias vel ceteras quae in solo publico sunt vendit, non solum, sed ius vendit, cum istae tabernae publicae sunt, quarum usus ad privatos pertinet. (El que vende negocios comerciales dedicados a la plata o todos los demás que están en suelo público, no vende el suelo sino el derecho de suelo porque son públicos estos negocios cuyo uso pertenece a los privados).

${ }^{56}$ Aceptamos el uso del término 'azienda di balneazione' como usa Cerami, Lezioni di diritto commerciale romano, cit. 55 porque si en el texto anterior se trataba de los utensilios (instrumentum) de un hotel (taberna cauponia), difícilmente el pasaje posterior habría se habría referido a un balneario de uso privado como el recordado por Séneca, dial. 9.9.7:...iam enim inter balnearia et thermas bybliotheca quoque ut necessarium domus ornamentum expolitur... Probablemente en el pasaje de Próculo, en el libro segundo de sus epístulas en D. 8.2.13 pr. se habría considerado un balneario a uso público cuando un personaje de nombre Hibero lo habría construído en su propiedad (insula) usando una pared común con el propietario de una bodega: quidam Hiberus nomine, qui habet post horrea mea insulam, balnearia fecit secundum parietem communem... F. Trisoglio, en el glosario de la obra de Plinio, Ep. 2,Torino, 1973, 1396, refiere que los propietarios de baños públicos podían ser personas de alto nivel social y las mismas alquilaban la actividad a otras personas que ofrecían el servicio a poco precio. Probablemente el texto de Neracio habría tenido como presupuesto un testador no propietario del locus, el cual concedía en legado los utensilios necesarios para la actividad comercial que consistía en el balneario para permitir al beneficiado de continuar a administrar tal actividad. El término usado para los establecimientos públicos es balnearia, así E. Saglio, s.v. balneum en Dictionaire des Antiquités Grecques et Romaines, 1, Paris, 1881, 652.

${ }^{57}$ Instrumento curvo de cuerno o de metal con el cual los romanos eliminaban el aceite que se aplicaban en los baños. Recuerda Svetonio, Aug. 80 el uso excesivo de este instrumento por parte del emperador: sed et callis quibusdam ex prurigine corporis adsiduoque et vehementi strigilis usu plurifariam concretis ad impetiginis formam.

${ }^{58}$ Objetos que pertenecían al legado de utensilios (instrumentum) de un balneario se encuentran citados en Pauli Sent. 3.6.65, además del personal (balneator) encontramos los scamna (taburetes), hypopodia (probablemente se refiere al lugar para sentarse podia?), fistulae (mangueras), miliaria (ollas), epitonia (llaves de agua), rotae aquariae (las ruedas con las que se lleva el agua del rio), iumenta quoque quibus ligna deferuntur (los caballos que llevan la leña para calentar el agua): instrumento balneatorio legato balneator ipse et scamna et hypopodia, fistulae, miliaria, epitonia, rotae aquariae, iumenta quoque quibus ligna deferuntur legato cedunt. 
Se afirmó que en el legado de utensilios de un balneario se comprende dentro de los utensilios del mismo el personal que forma parte del mismo, así como en los utensilios del fundo son considerados los guardabosques y los jardineros y en los utensilios del hotel, el gerente, porque los balnearios no pueden ofrecer el servicio sin los esclavos destinados a tal función.

Parecería probable considerar las palabras dictum est como una clara referencia al pensamiento de Neracio. Incluír el personal de servicio dentro de los utensilios del balneario fue afirmado en $D$. 33.7.13.1, los guardabosques (saltuarii) en D. 33.7.12.4 y además, debemos recordar que el jurista antonino, en el libro cuarto de las epístolas citado por Ulpiano en D. 33.7.12.35 incluía en el fundo provisto con todos los elementos necesarios para la producción (fundus instructus) los esclavos destinados al cultivo y al cuidado del casco de la hacienda, entre los que se encontraban los jardineros (topiarii) que eran considerados utensilios del fundo.

Para Neracio cualquier esclavo dedicado al servicio del balneario debía ser incorporado dentro de los utensilios (instrumentum) así como en todos los casos análogos recordados por Marciano y estudiados en esta investigación; Paulo, refiriéndose a otro argumento, libro secundo ad Vitellium en D. 33.7.14, en total sintonía con el pensamiento neraciano incluía también el fornacator (el esclavo que enciende las estufas): continetur autem et fornacator ${ }^{59}$.

\section{Reflexiones finales}

Las breves páginas dedicadas al legado de utensilios (instrumentum) bajo la perspectiva neraciana han llevado a reflexiones sobre el papel del jurista en este tipo de legado. Los aspectos importantes de su pensamiento según nuestra opinión son identificados a continuación:

a. Neracio alejándose del pensamiento de Labeón, representante de la escuela a la que pertenecía (libro primo piqanîn a Paulo epito-

\footnotetext{
${ }^{59}$ Respecto al fornacator o faber balnearius así como todo el personal que desempeña una función en tal lugar ver M. Wisseman, Das Personal des antiken römischen Bades en Glota, 61, 1984, 81ss. y I. Nielsen, Thermae et Balnea. The architecture and cultural history of roman public baths, Aarhus, 1990, 126 ss.
} 
matorum en D. 33.7.5), acepta la tesis de Sabino y Casio (en Ulpiano, libro vicesimo ad Sabinum en D. 33.7.12.27), en donde el concepto de fundo provisto con los elementos necesarios para la producción (fundus instructus) tendrá un valor más amplio respecto al de fundo con utensilios (fundus cum instrumento). La última frase de Sabino y Casio en sus notas a la obra de Vitelio (citado en D. 33.7.12.27) explica la tesis de Neracio sobre el argumento: todo aquello que se encuentre colocado para que el pater familias estuviera más cómodo o obtuviera más beneficios será incluído en el fundo provisto con los elementos necesarios para la producción (omnia quae eo collocata sunt, ut instructior esset pater familias, instructo, inquit, continebuntur).

b. Si bien el fundo provisto con los elementos necesarios para la producción (fundus instructus) estaba compuesto de diferentes elementos dentro de los cuales el casco de la hacienda (villa o praetorium) esta tiene una función central en el pensamiento de Neracio, no solamente como núcleo de una empresa agrícola, sino sobretodo como residencia del patrón en donde se encuentran los elementos necesarios para permitir al legatario la misma comodidad de la que gozaba el de cuius en vida (libro cuarto de sus epístolas citado por Ulpiano, libro vicesimo ad Sabinum en D. 33.7.12.35). Tal posición no se debe al hecho de que el jurista no tenga claras las fronteras entre utensilios del fundo (instrumentum fundi) e instrumentum patris familias, sino que el mismo reconoce el momento histórico en el que vive donde los dos tipos de utensilios (instrumenta) resultan imprescindibles.

c. Neracio no tenía la misma opinión de la demás jurisprudencia (Cascelio, Trebacio, Labeón, Javoleno y Ulpiano), que excluía el asno del molino y la piedra para moler como parte de los utensilios del fundo (Paulo, libro secundo ad Vitellium en D. 33.7.18.2). El jurista tenía tal opinión probablemente porque tales bienes no intervenían en manera directa en la producción agrícola; de todos modos estos objetos habrían sido incorporados en el concepto de fundo provisto con todos los elementos necesarios para la producción (fundus instructus). Diferentemente en la producción de aceite, el jurista antonino, en una carta dirigida a Aristón (recordada por Ulpiano, libro trigesimo secundo ad edictum en D. 19.2.19.2), incorporaba dentro de los utensilios (instrumentum) elementos que sirven para moler porque la cosecha de las aceitunas no concluye el proceso de producción sino que requiere de un paso siguiente consistente en la transformación del fruto en aceite. 
d. Los esclavos (mancipia) para ser incorporados dentro de los utensilios (instrumentum) habrían debido tener dos funciones según Neracio: cultivar la tierra y cuidar el casco de la hacienda. El jurista recordado por Ulpiano, libro vicesimo ad Sabinum en D. 33.7.12.4 habría aceptado la tesis de Labeón en donde el vigilante (saltuarius) tenía que vigilar los frutos y además incorpora otra función aceptada en jurisprudencia: custodiar los límites del fundo. El aumento de perspectiva se debía a la necesidad que existía en la agricultura intensiva en donde la vigilancia no se limitaba únicamente a los frutos sino que incluía además la tierra donde la semilla germina.

e. El legado con utensilios (cum instrumento) en la opinión de Neracio (Paulo, libro tertio ad Neratium en D. 33.7.24), incluye los utensilios (instrumentum) utilizados por el colono para trabajar la tierra, porque según el jurista, así como el testador habría tenido derecho a la posesión de los utensilios en el caso en que no fuera pagado el alquiler, también el legatario habría tenido el mismo derecho del que gozaba el de cuius en base al contrato.

f. El legado de casa provista con el mobiliario (domus instructa) según el pensamiento de Neracio (Ulpiano, libro vicesimo ad Sabinum en D.33.7.12.43) tiene como base de interpretación el fundo provisto con todos los elementos necesarios para la comodidad del pater familias (fundus instructus), porque la diferencia entre casco de hacienda (villa) y la casa (domus) es mínima (la primera se encuentra en el campo y la segunda en la ciudad). Por ello todos los objetos que pertenecían al testador en vida y destinados a su comodidad corresponderán al legatario, como por ejemplo el caso de la ropa. Si el testador hubiera excluído expresamente en la disposición objetos que existían dentro de la casa como la plata y las cuentas (argentum et rationes excepisse), todas las demás cosas deberían formar parte del legado según un criterio aplicable a todos los casos parecidos como el fundo provisto con los elementos necesarios para la producción (fundus instructus) y negocio listo para desempeñar su función económica (taberna instructa): nam qui haec, inquit, excepit, non potest non videri de ceteris rebus, quae in ea essent, sensisse.

g. Si bien no tenemos textos de Neracio sobre el negocio listo para desempeñar su función económica (taberna instructa), parece evidente, al mismo modo de lo que sucedería en un legado de fundo provisto con los elementos necesarios para la producción (fundus instructus) y de la casa amueblada (domus instructa), la incorporación del lugar 
en donde se ejercita la actividad comercial; y si el legado hubiera sido de los utensilios del negocio (instrumentum tabernae), se habría debido conocer, en la determinación de su contenido, el tipo de actividad desarrollada por el testador en vida, criterio declarado por el jurista en el segundo libro de sus responsos en D. 33.7.23. En los legados de los utensilios de un hotel (instrumentum de la taberna cauponia) y de los utensilios de un balneario, Neracio sin ninguna distinción (como contrariamente hace Paulo, libro quarto ad Sabinum en D. 33.7.13 pr.-1), incluye en su contenido los esclavos que desempeñan la función de dependientes (institores) o aquellos que auxilian a los clientes en los balnearios al mismo modo como sucedería con los utensilios del fundo (instrumentum fundi) en donde se encontraban incluidos los esclavos (mancipia) destinados al trabajo del fundo, criterio aceptado por Marciano, libro septimo institutionum en D. 33.7.17.2.

Sobre la vida de Neracio Prisco ver por ejemplo, W. Kunkel, Herkunft und soziale Stellung der römischen Juristen, Graz-Wien-Köln, 1967, 144 ss, F. Schulz, Storia della giurisprudenza romana, trad., Firenze, 1968, 190, F. Grelle, L'autonomia cittadina fra Traiano e Adriano, Napoli, 1972, 156 ss, F. Casavola, Giuristi Adrianei, Napoli, 1980, 272 ss, V. Scarano Ussani, Empiria e Dogmi. La scuola proculeiana fra Nerva e Adriano, rist. Torino, 1990, 21 ss, G. Camodeca, La carriera del giurista L. Neratius Priscus en AAN. 87, 1976, 32 ss., del mismo autor II giurista L.Neratius Priscus Cos. Suff. 97 nuovi dati su carriera e famiglia en SDHI, 73, 2007, 291 ss., T. Masiello, introducción a la obra de S. Nappi, lus finitum, Bari, 2005, 7 ss.

Sobre el legado de utensilios ver A. Steinwenter, Fundus cum instrumento. Eine agrar- und rechtsgeschichtliche Studie, Wien-Leipzig, 1942, 26 ss. V. Arangio-Ruiz, s.v. instrumentum en Dizionario epigrafico di antichitá romane, 4.1, Roma, 1946, 59 ss. P. Rasi, Le pertinenze e le cose accessorie, Padova, 1954, 28, M. Horvat, <<Servi >> e $<<$ legatum fundi >> nella giurisprudenza classica en Antologia giuridica romanistica ed antiquaria, 
1, Milano, 1968, 213 ss, del mismo autor, 'Legatum fundi' e 'servi' en Studi in onore di E. Volterra, 5, Milano, 1971, 89 ss, Astolfi, Studi sull'oggetto dei legati in diritto romano, 2, cit., 2 ss. M. A. Ligios, Interpretazione giuridica e realtá economica dell'<<instrumentum fundi >> tra il I sec. a.C. e il III sec.d.C., Napoli, 1996, 33 ss. 